\title{
A systematic review of parental attitude and preferences towards implementation of sexuality education
}

\author{
Yeo Kee-Jiar, Lee Shih-Hui
}

Faculty of Social Sciences \& Humanities, Universiti Teknologi Malaysia, Malaysia

\begin{tabular}{l} 
Article Info \\
\hline Article history: \\
Received Jul 19, 2020 \\
Revised Oct 2, 2020 \\
Accepted Oct 27, 2020 \\
\hline
\end{tabular}

\section{Keywords:}

Parental attitude

Parents

Preferences

Sexuality education

\begin{abstract}
Parents play a unique role in providing and facilitating their children in acquirement of sexual and reproductive health knowledge. The purpose of this study is to provide an overview of parents' attitude, preferences towards sexuality education (SE) and factors that contributed to their attitudes and perceptions based on review of relevant literature. The articles were retrieved via electronic databases, and manually examined to identify the studies that addressed the research questions. There were 29 studies with a total of 22,213 parents involved which published in peer-reviewed journals between the year 2000 and 2018 were selected and reviewed systematically. The findings emerged from the review were categorized into three main themes which included parental attitudes, parental preferences towards the implementation of SE and the factors contributed to their attitudes and perceptions. Most studies revealed that parents showed positive attitudes and support the inclusion of SE in school. They preferred age-appropriated SE to be introduced in elementary schools and secondary schools. Some parents supported SE which is aligned with religious teaching and cultural. Demographic factors, parents' sexuality knowledge, religious and cultural factors could affect parental attitudes and perceptions towards SE. This understanding could be useful for policymakers and educators to encourage collaboration with parents to strengthen the effectiveness of the program and scale up SE to benefit the young generation.
\end{abstract}

This is an open access article under the CC BY-SA license.

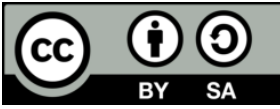

\section{Corresponding Author:}

Lee Shih-Hui,

School of Education,

Faculty of Social Sciences \& Humanities,

Universiti Teknologi Malaysia,

81300 Skudai, Johor, Malaysia.

Email: leeshihhui0606@gmail.com

\section{INTRODUCTION}

Sexuality education (SE) is defined as "a curriculum-based process of teaching and learning about cognitive, emotional, physical and social aspects of sexuality. It aims to equip children and young people with knowledge, skills, attitudes and values that will empower them to: realize their health, well-being and dignity; develop respectful social and sexual relationships; consider how their choices affect their own wellbeing and that of others; and, understand and ensure the protection of their rights throughout their lives" [1]. According to Sexuality Information and Education Council of the United States (SIECUS), SE programs have four main goals, which included: (a) to provide accurate information about human sexuality; (b) to support young people to develop and understand their value, attitudes and insights about sexuality; (c) to assist young people develop relationships and interpersonal skills and (d) to help young people exercise responsibility regarding sexual relationships [2]. Moreover, there is a need for children and young people to 
learn about the risk of sexual exploitation and abuse, so that they are able to protect themselves and identify and access available sources of support. The embarrassment and silence of parents and teachers in SE communication discourages youths in seeking knowledge regarding sexual and reproductive health [3]. Hence, the adolescents are confronted with confusing, conflicting and negative messages about sexuality when approaching adulthood. Past research also indicated that SE as a mediator to sensitize children, parents, teachers, police and local communities about the significance of sexual and reproductive health as well as potential solutions to sexual and reproductive health issues [4].

SE had been implemented for more than a few decades in some European countries, and the effectiveness of SE were acknowledged in many empirical studies. In contrast with the myths that SE will promote early sexual experimentation, it is found that SE does not accelerate sexual activity but promotes safer sexual behaviours and delay sexual debuts [5]. SE can be conducted in different approaches based on the differences of national policy and cultural context. There are mainly two types of approaches which namely, abstinence-only sexuality education (AOSE) and comprehensive sexuality education (CSE). CSE aims to equip the adolescents with the knowledge, skills, attitudes and values required to make informed choice and enjoy their sexuality physically, emotionally, individually and in their relationships [6]. CSE supports abstinence as the first and best choice for preventing pregnancy and sexually-transmitted diseases but also provides contraceptive methods to assist adolescents in decision-making [7]. On the other hand, AOSE teaches abstinence is the only method to prevent pregnancy and sexually-transmitted diseases. AOSE usually employs fear, shame and guilt strategies to exaggerate the negative consequences of sexual behaviours, negatively portray sexually-active youths and instil guilt and shame among the adolescents to prevent sexual behaviour [8].

High quality SE for youth are influenced by a combination of complex factors. Parents, the primary caregivers play essential role in the gender and social sexualization for their children. Their attitudes and support are significance for the successful implementation of SE [9]. The close attachment between parents and children and their communication on sexuality matters were identified as predictive factors of sexual and reproductive health outcomes such as engagement in risky sexual behaviours and sexual debut [10]. Moreover, school teachers consistently reported that parental factor as a challenge in implementation of sexuality education. The comprehensiveness and effectiveness of the teaching can be limited as the teachers are worrying about receiving backlash from the parents [11].

There is increasing number of studies examined the perceptions and attitudes of parents towards implementation of SE. These studies also investigated the preference of parents for introducing SE to school children and shed light on the factors could affect their attitudes. Several studies had explored the determinants related to parents' negative attitudes and perceptions towards sexuality education. Nevertheless, parent's attitude, preferences and factors associated with their attitudes were not systematically review. Thus, the purpose of this paper is to review the available literature on parental attitudes and perceptions on SE has not been systematically reviewed. Moreover, this review also attempts to identify the factors that could contribute to successful implementation of SE. The finding of this literature review could be useful in identifying research gaps for future study.

\section{RESEARCH METHOD}

To gather published articles for the study, online databases such as ScienceDirect, Taylor \& Francis Online, PubMed, Springer link, National Centre for Biotechnology Information (NCBI), JSTOR, EBSCO host and Google Scholar were used in data searching. During the process of searching, the keywords: 'sexual education', 'sexuality education', 'sexuality and health education; were paired with terms such as 'parents', 'parental perceptions', 'opinions', 'perspectives' and 'attitudes'. Since this study focused on the attitudes and perceptions of parents towards the implementation of school-based SE, the articles obtained from the search mentioned above were further examined manually to identify the articles which are related and appropriate. There are total 30 articles which fulfilled the criteria: 1) the studies involve parental attitudes and perceptions towards SE; 2) published in a peer-reviewed journal; 3) published between year 2000 and 2018 were adopted for this literature review. The articles were collected from different geographical boundaries to deepen the understanding towards the differences of parental attitude towards SE across different countries and cultures. These studies were further reviewed and categorized into themes based on the data reported which related to parental attitudes towards the program; preferences of SE in school (types of SE, age level for introductory of $\mathrm{SE}$ ); the relationship between demographic variables (gender of parents, age, level of education, socioeconomic status) and their attitudes and the challenges of SE implementation. 


\section{RESULTS}

The studies reported the parental attitudes and perceptions towards SE across North America, Europe, Africa, Australia and Europe. There were 23 from 29 study conducted the research by quantitative approach [12-32], three papers utilized qualitative [33-35] and the other three papers adopted mixed-method approach [36-38] to explore parental attitudes and perceptions on SE (Table 1). These studies involved the participation of parents with children who were attending preschool, primary school or high school. Nevertheless, some studies did not specifically indicate that the participants were parents of school children $[12,14,24,25,32,35]$. The findings of this review were organized according to the objectives of this study which related to parental attitudes towards SE, their preferences on how SE is conducted in school, demographic variables that could influence parental attitudes and other challenges in SE implementation.

Table 1. Research methodology of the included literatures

\begin{tabular}{|c|c|c|}
\hline Quantitative & Qualitative & Mixed-method \\
\hline 1. Achille et al. (2017) & 1. Do, Boonmongkon, Paek \& & 1. Fentahun, Assefa, Alemseged \& \\
\hline 2. Akpama (2013) & Guadamuz (2017) & Ambaw (2012) \\
\hline 3. Barr, Moore, Johnson, Forrest \& Jordan & 2. Jerves et al. (2014) & 2. Igor, Ines \& Aleksandar (2015) \\
\hline (2014) & 3. Wanje et al. (2017) & 3. Rahimah et al. (2009) \\
\hline 4. Bhuiyan (2014) & & \\
\hline 5. Constantine, Jerman \& Huang (2007) & & \\
\hline 6. Dake, Price, Baksovich \& Wielinski (2014) & & \\
\hline $\begin{array}{l}\text { 7. Eisenberg, Bernat, Bearinger \& Resnick } \\
\text { (2008) }\end{array}$ & & \\
\hline 8. Eko, Abeshi, Osonwa, Uwanede \& Offiong & & \\
\hline 9 Fsohe \& Peterinvang $(2015)$ & & \\
\hline 9. Esohe \& Peterınyang (2015) & & \\
\hline 10. Fisher (2015) & & \\
\hline 11. Ito et al. (2006) & & \\
\hline 12. Kantor \& Levitz (2017) & & \\
\hline 13. Lewis et al. (2001) & & \\
\hline 14. Liu, Dennis \& Edwards (2015) & & \\
\hline 15. Liu, van Campen, Edwards \& Russell & & \\
\hline$(2011)$ & & \\
\hline 16. MacBeth, Weerakoon, \& Sitharthan (2009) & & \\
\hline 17. McKay, Byers, Voyer, Humphreys \& & & \\
\hline Markham (2014) & & \\
\hline 18. Nair, et al. (2012) & & \\
\hline 19. Nyarko (2014) & & \\
\hline 20. Ogunjimi (2006) & & \\
\hline 21. Peter, Tasker \& Horn (2015) & & \\
\hline 22. Rob, Ghafur, Bhuiya \& Talukder (2005) & & \\
\hline 23. Weaver, Byers, Sears, Cohen \& Randall & & \\
\hline
\end{tabular}

\subsection{Parental attitude towards sexuality education}

Based on 29 papers reviewed, parents in 26 studies from various contexts showed positive attitude and supported the implementation of SE in school and at home. Nevertheless, some parents showed contradicted attitudes with the parents mentioned above, they did not want their children to receive SE in schools $[13,28,34]$

The parents who supported implementation of SE in schools acknowledged the significance of SE in reducing the rate of teenage pregnancy, tranmission of HIV/AIDS infections and abortions among adolescents [20, 29]. Moreover, the parents also believed that SE could equipped the young people with the skills to prevent sexual abuse and be prepared to make informed healthy decisions [19, 21]. But yet, the parents still showed concerns towards the negative consequences of SE such as sex-experimentation and earlier sexual debut $[20,38]$. Despite of the empirical evidence on SE benefits, there are parents opposed the implementation of school-based SE. They perceived SE will encourage immorality and expose them to early sexual intercourse $[13,19,22]$.

\subsection{Preferences regarding school-based sexuality education}

\subsubsection{Timing to introduce sexuality education}

Based on the review of twenty-nine studies, the findings showed that parents' preferences towards the timing to begin SE is varied. There are fourteen studies examined parents' opinions on the appropriate grade level to teach SE, 8 of the studies indicated that parents prefered the inclusion of SE in the school curriculum since elementary schools $[14,17,22,25,26,28,31,36,38]$ and parents in 2 studies stated that SE 
should begin as young as in preschool education and kindergarten [21, 24]. Two studies pointed out that parents thought secondary school is more appropriate to introduce SE among the students [18, 20]. Nevertheless, The parents also mentioned that SE should be age-appropriate $[17,21,36]$ and implemented based on the mental maturity of the students. They suggested that the SE should start from introduction of biological content among younger students and progress towards a more comprehensive content as age grows.

\subsubsection{Types of sexuality education}

This review also attempted to reveal parents' preferences towards the types of SE implemented in schools. Most of the parents from the studies reviewed shows favourable attitude towards CSE $[14,22-26,31]$ and indicated that the topics should be appropriate to the age of the students [17, 21]. In some conservative countries such as Malaysia and Bangladesh, the parents prefered CSE which is aligned with religious teaching, values and their cultural context $[15,38]$. There are also studies reported that parents prefered CSE but with a focus on abstinence $[18,20,30,36]$.

\subsubsection{Provider of sexuality education}

There are nine studies examines parents preferences on the appropriate personnel to provide SE. According to the findings, school is still considered as the most appropriate place to instill the knowledge of sexuality among the students $[33,34,38]$. The parents believed that school gurdian counsellor, doctors and nurses, and the school teachers are primarily responsible for provision of SE among the youths [20, 26, 27]. The parents also perceived that SE is a shared responsibility between parents and school teachers [28, 31]. Nevertheless, some parents also considered themselves especially for mothers [27,33] as competent source of SE and teaching sexuality knowledge to their children as their mission [12].

\subsection{Involvement of parents in sexuality education}

Thirteen articles from twenty-nine papers reviewed reported parents' perception towards their involvement and their experiences of providing SE at home. According to the analysis, most parents agreed the importance of SE for the well-being of adolescents and displayed high willingness to engage in their adolescents' SE, however, majority of them had not or rarely led discussions related to sexuality knowledge with their children $[12,27,31,35,39]$. They felt uncomfortable in communicating with their adolescents on matters regarding sexuality $[12,32,33,40]$. On the other hand, only two studies reported that the parents are comfortable to provide SE and possessed adequate knowledge to have good quality discussion about sexuality with their children $[21,26]$.

The barriers that hindered parents in discussing sexuality matters were being examined in this review also. The parents reported that lack of knowledge [27, 32, 34, 35, 39]; lack of communicative skills [12, 31]; adolescent know enough/ had learned about sexuality in school [12, 33]; not parental role to provide sexuality education/responsible of school $[12,28]$; children are too young to know about sexuality [28]; and lack of motivation to discuss sexuality with their children [12].

\subsection{Determinants of parental attitude towards sexuality education}

In order to deepen the understanding of parental attitude towards SE, the studies reviewed also examined on the determinants that can contributed to the formation parental attitude. Many studies indicated that gender of parents is a significant determinant in determining their attitudes towards SE. Generally, mothers showed more favourable attitude towards inclusion of SE in the school system, including the controversial topics such as contraceptions [14, 21, 22, 26, 38]. Mothers appeared to be more knowledgeable regards SE [26, 37] and more readily to engage in the discussion [35, 39]. Only one study out of the 29 articles reviewed showed that fathers were more positive about providing reproductive and sexual health information to their children [32].

Parents' education level could influence their attitude towards implementation of SE. However, the findings about parental education level on their atitude towards SE are not consistent. Some studies suggested that parents who had received higher education are more likely to acknowledge the significance of SE and support the teaching of SE in schools [12, 15, 16, 28]. Surprisingly, there are studies indicated that an inverse relationship was found between parental education and their support towards SE. Parents with higher education level showed hesitations towards the implementations of SE in schools whereas parents with lower education level displayed more positive attitude towards the program [14, 22, 38, 40]. Liu, et al. argued that educated Chinese parents are more likely to endorse traditional values that hinder the parents to discuss sexuality with their children [40]. Nevertheless, some studies showed that education level is not a significant determinant that contributed to parental attitude towards SE [18, 37, 39]. 
Parental attitudes towards SE could be influenced by parents' religious and cultural beliefs. The statement is supported by many prior studies which pointed out that there is a significant differences in parental attitudes based on their religious and cultural beliefs [12, 18, 34, 38, 40]. Liu and her colleagues pointed out that parents who endorsed traditional Chinese values and beliefs are more reluctant to discuss sexuality with their children [40]. Makol-Abdul et al. also supported that some parents did not want the inclusion of SE in school curriculum as they worried the teaching of sex-related knowledge is contradicted with the teaching of Islam [38].

Location of residence is also a potential determinant which could affect parental attitudes towards SE. Liu et al. stated that urban parents are more likely ascribed to traditional beliefs and values which could refrain them to discuss sexuality knowledge with their children [40]. Nevertheless, the findings from the other 2 studies showed that location of residence is not a significant determinant in predicting parental attitudes towards the inclusion of sexuality education in school curriculum [22, 28].

Based on the analysis, two studies revealed that income level of the parents significantly determined their attitudes on the implementation of SE. Parents with higher income were more supportive and showed more positive attitude on teaching of sexuality topics in schools [18, 39]. Parents' knowledge and familiarity towards SE could influenced their support towards SE [37,39]. The findings showed that parents with good sexual and reproductive health knowledge and familiar wilth the SE curriculum are more likely to show favourable attitude towards dissemination of sexuality knowledge among the adolescents.

\section{DISCUSSION}

This review is attempted to explore the parental attitude towards SE implementation in schools. Parents are identified as critical stakeholders in health and education policy affecting children, it is imperative to understand their views and opinions towards SE in order to gain their supports [18, 41]. The findings of this review suggested that the parents generally agreed the inclusion of SE in school. They acknowledged that the benefits of SE but yet, they are concerned about the negative consequences of the program as well. Constantine, et al. also argued that parents who had positive beliefs towards SE have higher odds to endorse the teaching of SE in schools [16]. As mentioned in the Health Belief Model, people are more likely to have positive attitude towards a health behaviour if they perceived the health behaviour is beneficial [42]. This finding is notable for the policy makers and educators who are promoting SE that introductory program to inform parents about the significance and benefits of the program is necessary to increase the efficiency of the implementation.

As the rapid development of technology, the adolescents are flooded with sexual content and information from various sources. Most of the information accessed by the adolescents could be incorrect and misleading which eventually leads to misconception and confusion about sexuality [43]. Hence, it is important for parents and teachers to play the role as gatekeeper in facilitate the uptake of knowledge about sexuality among the adolescents. Based on the review, although the parents had the willingness to engage in adolescents' SE, but they are facing with barriers that restrain them from doing so. The parents mentioned that lack of knowledge and skills, embarrassment, religious and cultural beliefs, lack of motivation, and their assumptions about young people are too young and they had learned the sexuality from other sources had further limit their initiatives in leading sexuality discussions with their adolescents. Therefore, the policy makers should aware of parents' difficulties in embracing SE and provide necessary supports to aid the parents. A collaborative report from UNFPA, UNESCO, \& WHO also stated that the teenagers are encountering unmet needs for comprehensive, acceptable and appropriate sexual and reproductive health information and exposure to abuse and violence due to sociocultural and religious norms [44].

In addition, this review also shed lights on the predictors which could influence parental attitudes towards SE. Although the findings were varied based on different context, however, prior studies reported that gender of parents, their education level, location of residence, age, religion and cultural beliefs, occupations and income did show significant differences in parental attitudes towards many aspects of SE. This review reported that mothers were more supportive towards the inclusion of SE and had higher involvement in sexuality discussion with their children than fathers. The favourable attitudes of mothers towards SE can be understood as they are the primary caregiver of the children, the closeness of the relationships allows them to have more conversations related to sexuality knowledge. However, there is a lack of empirical evidence specifically about fathers' opinion and role in instilling sexuality knowledge among the adolescents. Moreover, cultural and religious factors were identified as one of the most critical determinants that contributed to the negative attitudes of parents.

Prior study suggested that misconception and misinterpretation of religious teaching could lead to their refusal towards SE $[45,46]$. Therefore, the policy makers and implementers should adopt SE which is appropriate to their culture and context. At the same time, the efforts to eradicate the misconceptions and 
traditions which could lead to serious health issues should not be neglected in order to promote SE. This review also demonstrated that parents with lower socioeconomic status are more likely to develop negative attitude towards SE. Lower socioeconomic status might limited their access to SE [44, 47], hence, unfamiliarity of the program may lead to unfavourable parental attitude towards SE. Thus, this finding further highlighted the need for the access of SE and sexual and reproductive health services among the underserved populations, which could optimize their attitudes towards SE and eventually, improve the quality of life among the populations.

There are several limitations that need to be highlighted in this review. First, although the researcher had conducted searches in major electronic databases, but the searching strategies might potentially exclude some eligible articles. Second, this review only included the article published in English, thus, it is likely to neglect some valuable research on parental attitude towards SE which was published in other languages. Third, all the outcomes in this review were based on self-report data. Self-report data provides a richness of personalized data, enables the respondents to provide data with greater depth, reports on constructs that cannot be observed such as beliefs and attitudes and are relatively easy to collect [48]. However, self-report data sometimes can be inaccurate and lack of precision due to response bias and recall [49]. Last but not least, the included studies for this review were originated from different countries which consist of different cultural and social background. Schwartz and Robertson argued that the sexual expression and education may be differ according to national policy and cultural norms, these differences may potentially result in variability between the seemingly similar subjects in different countries [50].

\section{CONCLUSION}

Sexuality education (SE) is a cost-effective and fundamental method in improving the quality of health in a nation. SE not only equipped the adolescents with the knowledge and skills related to sexual and reproductive health, it also provides information for accessing sexual and reproductive health services. This study conducted a systematic review about parental attitudes and preferences towards the inclusion of SE in school. Parental supports are significant in implementation of policy which affects the adolescents, with their endorsement; the implementation of the program is more likely to have bigger impacts among the populations. The finding of this review is significance in highlighting the gap for future study. As mentioned above, parents are important stakeholders in determining the program related to children, it is significant to study their attitudes and opinions of the parents. Besides, the study also provides insights for policy makers on the potential determinants which could contribute to parental attitudes and preferences. Through the understanding, policy makers and educators can plan strategies to engage parents as a more active role in implementation of SE.

\section{ACKNOWLEDGEMENTS}

This work was supported by the Ministry of Higher Education Malaysia (MOHE) under the Fundamental Research Grant Scheme with reference code (FRGS/1/2019/SS05/UTM/01/1).

\section{REFERENCES}

[1] UNESCO, "International technical guidance on sexuality education: An evidence-informed approach," Paris 2018.

[2] Sexuality Information and Education Council of the United States (SIECUS), "Guidelines for Comprehensive Sexuality Education: Kindergarten through 12th Grade," Sexuality Information and Education Council of the United States, New York 2004.

[3] J. Wamoyi, A. Fenwick, M. Urassa, B. Zaba, and W. Stones, "Parent-child communication about sexual and reproductive health in rural Tanzania: Implications for young people's sexual health interventions," Reproductive health, vol. 7, article no. 6, 2010. [Online]. Available: https://doi.org/10.1186/1742-4755-7-6

[4] P. Gordon, "Sexuality education and the prevention of sexual violence," in Protecting Children From Sexual Violence - A Comprehensive Approach, Strasbourg Cedex: Council of Europe, pp. 175-186, 2011.

[5] UNESCO, "Review of the evidence on sexuality education: Report to inform the update of the UNESCO International technical guidance on sexuality education," UNESCO Education Sector, Paris, France, 2016.

[6] International Planned Parenthood Education, "IPPF Framework for Comprehensive Sexuality Education," IPPF, London, 2010.

[7] V. Pittman and A. Gahungu, "Comprehensive Sexuality Education or Abstinence-Only Education: Which Is More Effective?" Journal of Research for Educational Leaders, vol. 3, no. 2, pp. 60-91, 2006.

[8] K. L. Wilson, D. C. Wiley, and B. Rosen, "Texas Sexuality Education Instruction: Shame and Fear-Based Methodology," Journal of Health Education Teaching, vol. 3, no. 1, pp. 1-10, 2012.

[9] S. Bastien, L. J. Kajula, and W. W. Muhwezi, "A review of studies of parent-child communication about sexuality and HIV/AIDS in sub-Saharan Africa," Reproductive health, vol. 8, no. 25, pp. 1-17, 2011. 
[10] C. M. Markham, et al., "Connectedness as a predictor of sexual and reproductive health outcomes for youth," Journal of adolescent health, vol. 46, no. 3, pp. S23-S41, 2010.

[11] R. L. Johnson, M. C. Sendall, and L. A. McCuaig, "Primary schools and the delivery of relationships and sexuality education: the experience of Queensland teachers," Sex Education, vol. 14, no. 4, pp. 359-374, 2014.

[12] O. Achille, B. Tonato, K. Salifou, A. Hounkponou, and B. Hounkpatin, "Parents' Perceptions and Practices as Regards Adolescents' Sex Education in the Home Environment in the City of Come, Benin in 2015," Reprod Syst Sex Disord, vol. 6, no. 2, pp. 1-6, 2017.

[13] E. G. Akpama, "Parental Percetion of the Teaching of Sex Education to Adolescent in Secondary School in Cross River State, Nigeria," Himalayan Journal of Sociology and Anthropology, vol. 6, pp. 134-145, 2014.

[14] E. M. Barr, M. J. Moore, T. Johnson, J. Forrest, and M. Jordan, "New evidence: data documenting parental support for earlier sexuality education," Journal of School Health, vol. 84, no. 1, pp. 10-17, 2014.

[15] M. K. Bhuiyan, "Inclusion of Sex Education in School Curriculum of Bangladesh: Parents' Attitude," IOSR Journal of Research \& Method in Education, vol. 4, no. 5, pp. 32-40, 2014.

[16] N. A. Constantine, P. Jerman, and A. X. Huang, "California parents' preferences and beliefs regarding schoolbased sex education policy," Perspectives on Sexual and Reproductive Health, vol. 39, no. 3, pp. 167-175, 2007.

[17] J. A. Dake, J. H. Price, C. M. Baksovich, and M. Wielinski, "Preferences Regarding School Sexuality Education Among Elementary Schoolchildren's Parents," American Journal of Health Education, vol. 45, no. 1, pp. 29-36, 2014.

[18] M. E. Eisenberg, D. H. Bernat, L. H. Bearinger, and M. D. Resnick, "Support for comprehensive sexuality education: Perspectives from parents of school-age youth," Journal of Adolescent Health, vol. 42, no. 4, pp. 352-359, 2008.

[19] E. Eko Jimmy, S. Abeshi, O. Osonwa Kalu, C. Uwanede, and A. Offiong Dominic, "Perception of Students' Teachers' and Parents' towards Sexuality Education in Calabar South Local Government Area of Cross River State, Nigeria," Journal of Sociological Research, vol. 4, no. 2, pp. 222-240, 2013.

[20] K. P. Esohe and M. P. Inyang, "Parents Perception of the Teaching of Sexual Education in Secondary Schools in Nigeria," International Journal of Innovative Science, Engineering \& Technology, vol. 2, no. 1, pp. 89-99, 2015.

[21] C. M. Fisher, S. K. Telljohann, J. H. Price, J. A. Dake, and T. J. Glassman, "Perceptions of Elementary School Children's Parents Regarding Sexuality Education," American Journal of Sexuality Education, vol. 10, pp. 1-20, 2015.

[22] K. E. Ito, Z. Gizlice, J. Owen-O'Dowd, E. Foust, P. A. Leone, and W. C. Miller, "Parent opinion of sexuality education in a state with mandated abstinence education: Does policy match parental preference?" Journal of Adolescent Health, vol. 39, no. 5, pp. 634-641, 2006.

[23] L. Kantor and N. Levitz, "Parents' views on sex education in schools: How much do Democrats and Republicans agree?" PloS one, vol. 12, no. 7, p. e0180250, 2017.

[24] R. K. Lewis, A. Paine-Andrews, C. Custard, M. Stauffer, K. Harris, and J. Fisher, "Are parents in favor or against school-based sexuality education? A report From the Midwest," Health Promotion Practice, vol. 2, no. 2, pp. 155-161, 2001.

[25] A. Macbeth, P. Weerakoon, and G. Sitharthan, "Pilot study of Australian school-based sexual health education: Parents' views," Sexual Health, vol. 6, no. 4, pp. 328-333, 2009.

[26] A. McKay, E. S. Byers, S. D. Voyer, T. P. Humphreys, and C. Markham, "Ontario parents' opinions and attitudes towards sexual health education in the schools," The Canadian journal of human sexuality, vol. 23, no. 3 , pp. 159-166, 2014.

[27] M. Nair, et al., "Attitude of parents and teachers towards adolescent reproductive and sexual health education," The indian journal of pediatrics, vol. 79, no. 1, pp. 60-63, 2012.

[28] K. Nyarko, K. I. Adentwi, M. Asumeng, and L. D. Ahulu, "Parental attitude towards sex education at the lower primary in Ghana," International Journal of Elementary Education, Vol. 3, No. 2, pp. 21-29, 2014.

[29] D. Ogunjimi, "Attitude of students and parents towards the teaching of sex education in secondary schools in Cross Rivers State," Educational Research and Reviews, vol. 1, no. 9, pp. 347-349, 2006.

[30] C. R. Peter, T. B. Tasker, and S. S. Horn, "Parents' attitudes toward comprehensive and inclusive sexuality education: Beliefs about sexual health topics and forms of curricula," Health Education, vol. 115, no. 1, pp. 71-92, 2015.

[31] A. D. Weaver, E. S. Byers, H. A. Sears, J. N. Cohen, and H. E. Randall, "Sexual health education at school and at home: Attitudes and experiences of New Brunswick parents," Canadian Journal of Human Sexuality, vol. 11, no. 1, pp. 19-32, 2001.

[32] U. Rob, T. Ghafur, I. Bhuiya, and M. N. Talukder, "Reproductive and sexual health education for adolescents in Bangladesh: parents' view and opinion," International Quarterly of Community Health Education, vol. 25, no. 4, pp. 351-365, 2006.

[33] L. A. T. Do, P. Boonmongkon, S. C. Paek, and T. E. Guadamuz, "'Hu Hong'(bad thing): parental perceptions of teenagers' sexuality in urban Vietnam," BMC public health, vol. 17, no. 1, p. 226, 2017.

[34] E. Jerves et al., "Understanding parental views of adolescent sexuality and sex education in Ecuador: A qualitative study," Sex Education, vol. 14, no. 1, pp. 14-27, 2014.

[35] G. Wanje, L. Masese, E. Avuvika, A. Baghazal, G. Omoni, and R. S. McClelland, "Parents' and teachers' views on sexual health education and screening for sexually transmitted infections among in-school adolescent girls in Kenya: a qualitative study," Reproductive health, vol. 14, no. 1, pp. 1-11, 2017.

[36] N. Fentahun, T. Assefa, F. Alemseged, and F. Ambaw, "Parents' perception, students' and teachers' attitude towards school sex education," Ethiopian journal of health sciences, vol. 22, no. 2, pp. 99-106, 2012. 
[37] K. Igor, E. Ines, and Š. Aleksandar, "Parents' attitudes about school-based sex education in Croatia," Sexuality Research and Social Policy, vol. 12, no. 4, pp. 323-334, 2015.

[38] P. R. Makol-Abdul, A. S. Nurullah, S. S. Imam, and S. A. Rahman, "Parents' attitudes towards inclusion of sexuality education in Malaysian schools," International Journal about Parents in Education, vol. 3, no. 1, pp. 42-56, 2009.

[39] W. Liu, K. S. Van Campen, C. P. Edwards, and S. T. Russell, "Chinese parents' perspectives on adolescent sexuality education," International Journal of Sexual Health, vol. 23, no. 3, pp. 224-236, 2011.

[40] W. Liu, J. M. Dennis, and C. P. Edwards, "Chinese parents' involvement in sexuality education for adolescents," International Journal of Sexual Health, vol. 27, no. 4, pp. 485-507, 2015.

[41] M. E. Eisenberg, N. Madsen, J. A. Oliphant, and M. Resnick, "Policies, principals and parents: multilevel challenges and supports in teaching sexuality education," Sex Education, vol. 12, no. 3, pp. 317-329, 2012.

[42] I. M. Rosenstock, V. J. Strecher, and M. H. Becker, "Social learning theory and the health belief model," Health education quarterly, vol. 15, no. 2, pp. 175-183, 1988.

[43] E. Gruber and J. W. Grube, "Adolescent sexuality and the media: a review of current knowledge and implications," The Western journal of medicine, vol. 172, no. 3, pp. 210-214, 2000.

[44] UNFPA, UNESCO, and WHO, "Sexual and reproductive health of young people in Asia and the Pacific: A review of issues, policies and programmes," Bangkok, 2015.

[45] S. Koral, "Cultural, religious and socio-economic factors affecting sex education in Turkey," Planned parenthood in Europe = Planning familial en Europe, vol. 20, no. 1, pp. 15-16, 1991.

[46] K. J. Yeo, S. H. Lee, and L. Handayani, "Effort of NGO in Promoting Comprehensive Sexuality Education to Improve Quality of Life among Local and Refugee Communities," International Journal of Evaluation and Research in Education, vol. 7, no. 1, pp. 17-24, 2018.

[47] A. M. Minnis, et al., "Limited socioeconomic opportunities and Latina teen childbearing: a qualitative study of family and structural factors affecting future expectations," Journal of Immigrant and Minority Health, vol. 15, no. 2, pp. 334-340, 2013.

[48] D. Dodd-McCue and A. Tartaglia, "Self-report response bias: Learning how to live with its diagnosis in chaplaincy research," Chaplaincy Today, vol. 26, no. 1, pp. 2-8, 2010.

[49] G. D. Gaskell, D. B. Wright, and C. A. O'Muircheartaigh, "Telescoping of landmark events: implications for survey research," The Public Opinion Quarterly, vol. 64, no. 1, pp. 77-89, 2000.

[50] R. J. Schwartz and R. E. Robertson, "A review of research on sexual education for adults with intellectual disabilities," Career Development and Transition for Exceptional Individuals, vol. 42, no. 3, pp. 148-157, 2019.

Int. J. Eval. \& Res. Educ. Vol. 9, No. 4, December 2020: 971 - 978 